Check for updates

Cite this: RSC Adv., 2018, 8, 40883

Received 23rd October 2018

Accepted 30th November 2018

DOI: $10.1039 / \mathrm{c} 8 \mathrm{ra0} 8753 a$

rsc.li/rsc-advances

\section{High efficiency hybrid white organic light-emitting diodes based on a simple and efficient exciton regulation emissive layer structure $\uparrow$}

\author{
Yuwen Chen, (D) Shian Ying, (D) Qian Sun, (D) Yanfeng Dai, Xianfeng Qiao, \\ Dezhi Yang, (iD) Jiangshan Chen and Dongge Ma*
}

It is well-known that hybrid white organic light-emitting diodes (WOLEDs) are constructed by blue fluorophors and red-green or orange phosphors, therefore, theoretically exhibiting the advantages of long lifetime and high efficiency. However, the efficiency is far from reaching the expected values. Here, we designed a simple and efficient exciton regulation emissive layer (EML) structure to fabricate high efficiency hybrid WOLEDs. The EML sequentially comprises a yellow EML of phosphor doped holetransporting material, a blue EML of a blend of hole- and electron-transporting materials and an exciton regulation layer of ultra-thin green phosphor inserted in electron-transporting material. It can be seen that the emissive excitons are well regulated by such a strategic EML structure. The resulting WOLEDs exhibit a maximum forward viewing external quantum efficiency and power efficiency of $18.2 \%$ and 72.9 $\mathrm{Im} \mathrm{W}^{-1}$, respectively, and they are as high as $16.7 \%$ and $61.7 \mathrm{Im} \mathrm{W}^{-1}$ at $100 \mathrm{~cd} \mathrm{~m}^{-2}$, and $12.5 \%$ and 37.7 $\mathrm{Im} \mathrm{W}^{-1}$ at $1000 \mathrm{~cd} \mathrm{~m}^{-2}$, showing the positive properties of high efficiency and low efficiency roll-off. Such outstanding performance will greatly promote the development of high performance hybrid WOLEDs.

\section{Introduction}

It is known that organic light-emitting diodes (OLEDs) have been the subject of a great deal of research since C. W. Tang demonstrated the first OLED in $1987^{1}$ and J. Kido reported the first white OLED (WOLED) in $1994 .^{2}$ Academia and industry have been devoted to the improvement of electroluminescence (EL) efficiency and long term stability of fabricated OLEDs. WOLEDs have been known to be an ideal lighting source because of the advantages of no shadows, soft light, no blue light damage, large area, flexibility and transparency. Therefore, it is urgent to further improve the efficiency and stability of WOLEDs in order to satisfy the requirement of practical application in lighting fields.

Currently, three types of WOLEDs are reported according to the employed emissive materials, including all-phosphorescent WOLEDs, all-fluorescent WOLEDs and fluorescent/phosphorescent hybrid WOLEDs. ${ }^{3}$ To enhance the efficiency, the utilization of phosphors is desirable since they can allow a conversion of up to $100 \%$ of injected charges into emitted photons,

Institute of Polymer Optoelectronic Materials and Devices, State Key Laboratory of Luminescent Materials and Devices, South China University of Technology, Guangzhou, 510640, People's Republic of China. E-mail: msdgma@scut.edu.cn

$\dagger$ Electronic supplementary information (ESI) available: Performance and the EL spectra of the devices with different buffer layers. PL transient decay curves of $\operatorname{Ir}(\text { tptpy })_{2}$ (acac) observed at $559 \mathrm{~nm}$. And $J-V$ characteristics of the devices with different thicknesses of UTL. See DOI: 10.1039/c8ra08753a resulting in a theoretical internal quantum efficiency of unity. ${ }^{4}$ Unfortunately, there are no ideal blue phosphorescent emitters in terms of lifetime and stability up to now. This restricts the development of all-phosphorescent WOLEDs, which is a major challenge. ${ }^{5}$ As we know, conventional blue fluorophors show good stability, therefore, the hybrid WOLEDs with stable blue fluorescent emitters combining high efficiency long wavelength phosphorescent emitters become the best choice. Hybrid WOLEDs can be achieved by incorporating either two complementary colours (blue and yellow or orange) or three primary colours (blue, green and red) in two architectures, including single-emissive-layer (single-EML) structures, ${ }^{6,7}$ or multiemissive-layers (multi-EML) structures. ${ }^{8}$ However, as we see, the efficiencies of all reported hybrid WOLEDs are basically less than $60 \mathrm{~lm} \mathrm{~W}^{-1}$, and the efficiency roll-off at high luminance is also very severe..$^{9-11}$

In this work, we fabricated high efficiency hybrid WOLEDs by strategically designing a simple and efficient exciton regulation emissive layer (EML) structure. It can be seen that not only the efficiency, but also the efficiency roll-off at high luminance are improved by the efficient control of exciton recombination zone in the blue fluorescent EML and the regulation role of the inserted ultrathin green phosphorescent layer in the excitons. The resulting hybrid WOLEDs shows a maximum external quantum efficiency and power efficiency of $18.2 \%$ and $72.9 \mathrm{~lm} \mathrm{~W}^{-1}$, and they are as high as $16.7 \%$ and $61.7 \mathrm{~lm} \mathrm{~W}^{-1}$ at $100 \mathrm{~cd} \mathrm{~m}^{-2}$, and $12.5 \%$ and $37.7 \mathrm{~lm} \mathrm{~W}^{-1}$ at $1000 \mathrm{~cd} \mathrm{~m}^{-2}$, respectively. 


\section{Experimental methods}

\subsection{Materials information}

Dipyrazino[2,3-f:2', $\left.3^{\prime}-h\right]$ quinoxaline-2,3,6,7,10,11-hexacarbonitrile (HAT-CN) as the hole injection material, $N, N^{\prime}$-di-(1-naphthalenyl)-

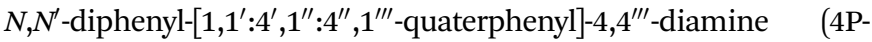
NPD) as the yellow phosphorescent dopant host and blue emitter, di-[4-(N,N-ditolyl-amino)-phenyl]cyclohexane (TAPC) as the hole-transporting material, and bis[2-(2-hydroxyphenyl)pyridine]beryllium $\left(\mathrm{Bepp}_{2}\right)$ as the blue-emitting electron transport material were purchased from Jilin OLED Material Tech Co. Ltd. The yellow phosphorescent dopant iridium(III)bis(4-(4-t-butylphenyl)thieno[3,2-c]pyridinato- $\left.N, \mathrm{C} 2^{\prime}\right)$ acetylacet-onate $\left(\operatorname{Ir}(\text { tptpy })_{2}(-\right.$ acac)) and green phosphorescent dopant bis(2-phenylpyridinato$N, \mathrm{C} 2)$ iridium(acetylacetonate) $\quad\left(\operatorname{Ir}(\mathrm{ppy})_{2}(\mathrm{acac})\right)$ were purchased from Luminescence Technology. All materials were used without further purification. The chemical structures of all organic materials and the blue OLED device structure are shown in Fig. S1. $\dagger$

\subsection{Device fabrication}

All devices were fabricated on glass substrates pre-coated by a $180 \mathrm{~nm}$ thick layer of indium tin oxide (ITO) with a sheet resistance of $10 \Omega$ per square. The ITO glass substrates were cleaned sequentially by using detergent and deionized water before use. Prior to the thin-film deposition, the substrates were treated with oxygen plasma for $3 \mathrm{~min}$ to improve the work function after dried at $120{ }^{\circ} \mathrm{C}$. Afterwards, the ITO glass substrates were loaded into a vacuum chamber for organic layer deposition by thermal evaporation under a base pressure of $5 \times$ $10^{-4} \mathrm{~Pa}$. The film thickness and deposition rates of the functional materials were monitored by a calibrated crystal quartz sensor. The deposition rates of organic layers, Liq, and $\mathrm{Al}$ were controlled at about $1 \AA \mathrm{s}^{-1}, 0.1 \AA \mathrm{s}^{-1}$, and $4-6 \AA_{\mathrm{s}}^{-1}$, respectively. For the case of doping or blending of two materials together, they were co-evaporated by respectively controlling their evaporation rate in two individual heaters at a certain ratio. The ultrathin layers were fabricated by very low evaporation rate of 0.01-0.02 $\AA^{-1}$. The overlap between ITO anode and Al cathode was $4 \mathrm{~mm} \times 4 \mathrm{~mm}$ as the active emissive area. Moreover, all organic films for PL test were prepared by vacuum evaporation on the quartz substrate.

\subsection{Measurement}

The current-luminance-voltage characteristics were measured by using a computer-controlled source meter (Keithley 2400) equipped with a light intensity meter LS-110 under ambient atmosphere without encapsulation. The EL spectra were measured by a Spectrascan PR650 spectrophotometer. The EQEs were calculated from the luminance, current density, and EL spectrum, assuming a Lambertian distribution. The photophysical properties, including UV/vis absorption, photoluminescence (PL), and excitation spectra were measured by a Shimadzu UV-2600 spectrophotometer, and an Edinburgh Instruments FLS 980 spectro-fluorometer. Additionally, the PL transient decay curves of the films were performed on Quantaurus-Tau fluorescence lifetime measurement system
(C11367-03, Hamamatsu Photonics Co.). All the results of devices were measured in the forward-viewing direction and all the measurements were carried out under an ambient atmosphere without encapsulation.

\section{Results and discussion}

\subsection{Structure and performance of blue OLEDs}

To make high-performance hybrid WOLEDs, it is very important to first optimize the blue emission property. ${ }^{\mathbf{1 2}}$ Therefore, choosing good blue fluorescent materials is considered. In our study, $N, N^{\prime}$-di-1-naphthalenyl- $N, N^{\prime}$-diphen- $\left[1,1^{\prime}: 4^{\prime}, 1^{\prime \prime}: 4^{\prime \prime}, 1^{\prime \prime \prime}\right.$-quaterphenyl]-4,4"'-diamine (4P-NPD), a deep blue emitter with a dominant emission peak at $425 \mathrm{~nm}$, high triplet energy level (2.3 eV) and high PLQY (92\%) as well as bis[2-(2-hydroxyphenyl)pyri-dine]beryllium $\left(\right.$ Bepp $\left._{2}\right)$, a deep blue emitter possessing a high fluorescent quantum yield of $>80 \%$ and a high triplet energy level $(2.6 \mathrm{eV})^{13}$ were selected to fabricate the efficient blue OLEDs.

As known to all, both $4 \mathrm{P}-\mathrm{NPD}$ and $\mathrm{Bepp}_{2}$ with deep-blue fluorescent emitters are widely used in OLEDs. ${ }^{14-16}$ To demonstrate the viability of $4 \mathrm{P}-\mathrm{NPD}$ and $\mathrm{Bepp}_{2}$ as blue emitters, we mixed 4P-NPD and Bepp $_{2}$ to fabricate blue OLEDs by optimizing different blending ratios. The device structure is ITO/HAT-CN $(15 \mathrm{~nm}) / \mathrm{TAPC}:$ HAT-CN $(4 / 2,95 \mathrm{~nm}) / \mathrm{TAPC} \quad(40 \mathrm{~nm}) / 4 \mathrm{P}-$ $\mathrm{NPD}: \mathrm{Bepp}_{2}(X, 13 \mathrm{~nm}) / \mathrm{Bepp}_{2}(5 \mathrm{~nm}) / \mathrm{Bepp}_{2}: \operatorname{Liq}(4.5 \%, 50 \mathrm{~nm}) /$ Liq $(1.25 \mathrm{~nm}) / \mathrm{Al}(120 \mathrm{~nm})$, where $X$ is $1: 0,2: 1,1: 1$, and $1: 2$, corresponding to device B1, B2, B3 and B4, respectively. In these devices, considering that 4P-NPD shows good hole transporting capacity with a high mobility of $6.6 \times 10^{-4} \mathrm{~cm}^{2} \mathrm{~V}^{-1} \mathrm{~s}^{-1}, 8$ and Bepp $_{2}$ exhibits excellent electron transporting capacity with a high mobility of $10^{-4} \mathrm{~cm}^{2} \mathrm{~V}^{-1} \mathrm{~s}^{-1},{ }^{17}$ we use TAPC (di-[4- $(N, N$ ditolyl-amino)-phenyl]cyclohexane) with higher mobility (about $10^{-2} \mathrm{~cm}^{2} \mathrm{~V}^{-1} \mathrm{~s}^{-1}$ ) as the electron-blocking layer (EBL), ${ }^{18}$ and hole-transporting layer (HTL) in the blue devices. And TAPC has a low refractive index, a high $\mathrm{T}_{1}$ of $2.87 \mathrm{eV}$ and a high LUMO (2.0 $\mathrm{eV}$, which will well confine excitons and light coupling output. ${ }^{19}$ Fig. S1† illustrates the blue device structure. The chemical structures of all organic materials used in this study are given in Fig. S2. $\dagger$

Fig. 1(a) shows the current density-luminance-voltage $\left(J-L^{-}\right.$ $V$ ) characteristics of the resulting blue OLEDs with different blending ratios. Clearly, they show the same turn-on voltage of $2.8 \mathrm{~V}$, and the higher concentration of $4 \mathrm{P}-\mathrm{NPD}$ in this blend leads to the higher luminance and bigger injection current density. The blue device with $2: 1$ concentration ratio emits the maximum luminance of $7880 \mathrm{~cd} \mathrm{\textrm {m } ^ { - 2 }}$. Fig. 1(b) shows the normalized EL spectra of devices B1-B4 at a driving voltage of $4 \mathrm{~V}$. It can be found that all devices emit blue light at a peak wavelength of about 427 with wide peak at long wavelength besides device B1. Obviously, the long wavelength emission

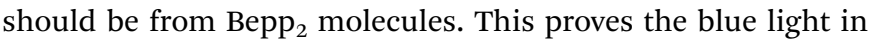
devices B2-B4 from the simultaneous emission of 4P-NPD and Bepp $_{2}$ molecules.

Fig. 1(c) and (d) describe the current efficiency-power efficiency-luminance (CE-PE-L) and the EQE-luminance (EQE-L) characteristics of the four blue devices. The detailed EL 
(a)

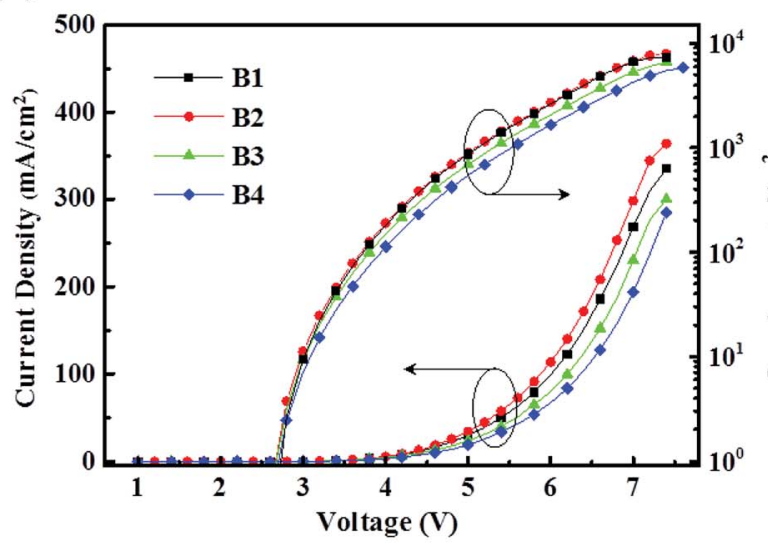

(c)

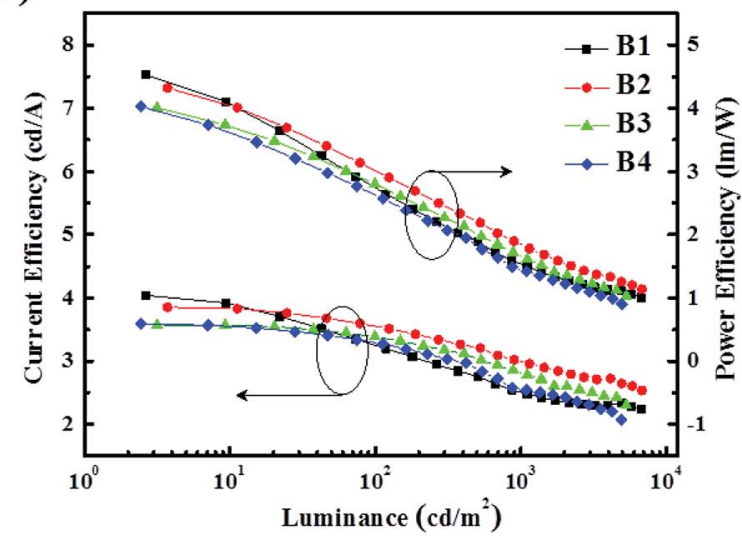

(b)

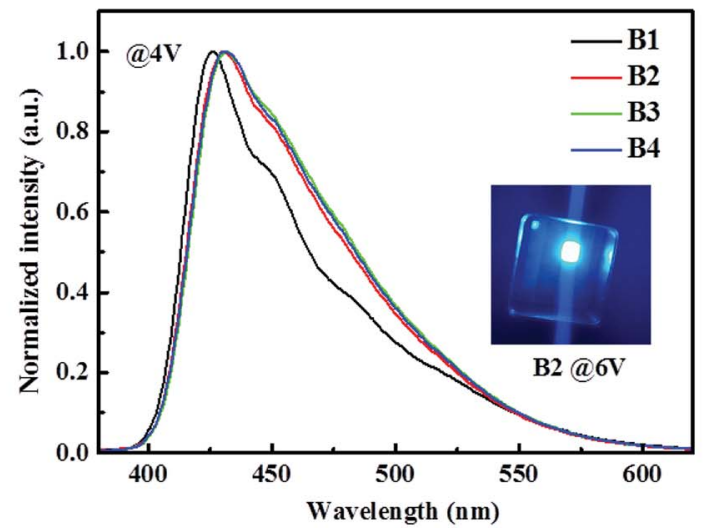

(d)

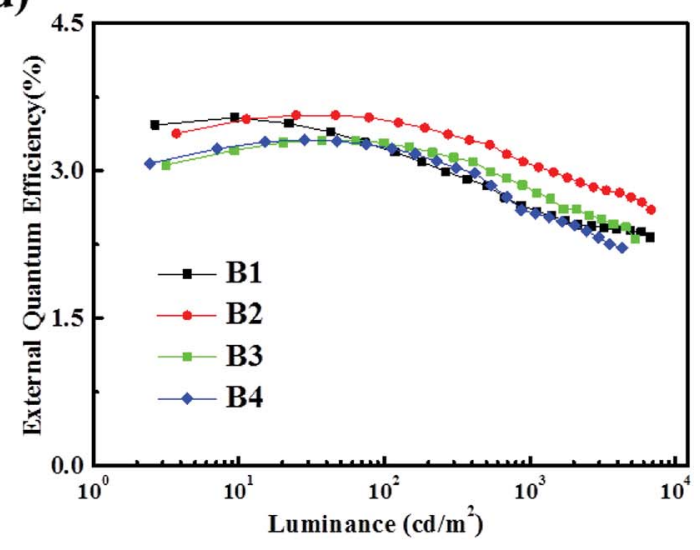

Fig. 1 (a) Current density-luminance-voltage $(J-L-V$ characteristics of the resulting four blue OLEDs. (b) Normalized EL spectra of the resulting four blue OLEDs at $4 \mathrm{~V}$. The inset shows the EL emission image of the blue device B2 at $6 \mathrm{~V}$. (c) Current efficiency-power efficiencyluminance (CE-PE-L) characteristics of the resulting four blue OLEDs. (d) External quantum efficiency versus luminance (EQE-L) characteristics of the resulting four blue OLEDs.

performance parameters are summarized in Table 1. It's pretty obvious that the device $\mathrm{B} 2$ emits higher efficiencies, and also shows a lower efficiency roll-off at high luminance than the others under the same condition. The EQE of device $\mathrm{B} 2$ reaches the maximum value of $3.56 \%$ and keeps $3.03 \%$ at $1000 \mathrm{~cd} \mathrm{~m}^{-2}$ luminance, indicating the important role of the concentration ratio of $4 \mathrm{P}-\mathrm{NPD}$ and $\mathrm{Bepp}_{2}$ blend. It can be seen that these devices also exhibit better pure blue emission with CIE $(0.15$, 0.12), which should be suitable for the preparation of WOLEDs.

As we see, $4 \mathrm{P}-\mathrm{NPD}$ and $\mathrm{Bepp}_{2}$ have the same highest occupied molecular orbital (HOMO) (5.70 eV for 4P-NPD and Bepp 2 ) energy levels, whereas the small energy offset $(\sim 0.3 \mathrm{eV})$ of lowest unoccupied molecular orbital (LUMO) (2.30 eV for 4P-NPD and $2.60 \mathrm{eV}$ for $\mathrm{Bepp}_{2}$ ) energy levels. ${ }^{16}$ In addition, owing to the approximate carrier transporting abilities of $4 \mathrm{P}-\mathrm{NPD}$ and Bepp 2 and the good exciton confine property of TAPC, the main exciton generation zone should be located within the mixed blue emitting layer.

Thus, we explored the exciton distribution profile in the 4PNPD : Bepp $_{2}$ blue EML by using the structure of ITO/HAT-CN $(15 \mathrm{~nm}) /$ TAPC : HAT-CN $\quad(4 / 2,95 \mathrm{~nm}) /$ TAPC $(40 \mathrm{~nm}) / 4 \mathrm{P}-$ NPD : Bepp Bep $_{2} \quad(2: 1, \quad X \quad \mathrm{~nm}) / \operatorname{Ir}(\text { tptpy })_{2}($ acac $) \quad(0.08 \mathrm{~nm}) / 4 \mathrm{P}-$ NPD : Bepp $_{2}(2: 1,13-X \mathrm{~nm}) /$ Bepp $_{2}(5 \mathrm{~nm}) /$ Bepp $_{2}: \operatorname{Liq}(4.5 \%, 50$ $\mathrm{nm}) / \mathrm{Liq}(1.25 \mathrm{~nm}) / \mathrm{Al}$, where $X$ varies from 0 to $13 \mathrm{~nm}$ with an

Table 1 Summary of EL performances of the resulting four blue OLEDs

\begin{tabular}{|c|c|c|c|c|c|c|c|}
\hline \multirow[b]{2}{*}{ Device } & \multirow[b]{2}{*}{$V_{\mathrm{on}}{ }^{a}(\mathrm{~V})$} & \multirow[b]{2}{*}{$L_{(\max )}\left(\mathrm{cd} \mathrm{m}^{-2}\right)$} & \multicolumn{3}{|c|}{ Max/@100 cd m ${ }^{-2} / @ 1000 \mathrm{~cd} \mathrm{~m}^{-2}$} & \multirow[b]{2}{*}{$\operatorname{Peak}^{b}(\mathrm{~nm})$} & \multirow[b]{2}{*}{$\operatorname{CIE}^{b}(x, y)$} \\
\hline & & & $\mathrm{CE}\left(\mathrm{cd} \mathrm{A}^{-1}\right)$ & $\mathrm{PE}\left(\operatorname{lm} \mathrm{W}^{-1}\right)$ & EQE $(\%)$ & & \\
\hline B2 & 2.8 & 7887 & $3.85 / 3.51 / 2.96$ & $4.32 / 2.90 / 1.78$ & $3.56 / 3.49 / 3.03$ & 430 & $(0.15,0.12)$ \\
\hline B3 & 2.8 & 6713 & $3.57 / 3.32 / 2.78$ & $4.01 / 2.61 / 1.62$ & $3.31 / 3.24 / 2.77$ & 432 & $(0.16,0.12)$ \\
\hline B4 & 2.8 & 5852 & $3.59 / 3.27 / 2.54$ & $4.03 / 2.57 / 1.43$ & $3.31 / 3.22 / 2.56$ & 430 & $(0.16,0.12)$ \\
\hline
\end{tabular}

${ }^{a}$ Turn-on voltage estimated at a brightness of $>1 \mathrm{~cd} \mathrm{~m}^{-2} .{ }^{b}$ Emission peak and the corresponding CIE coordinates obtained at a voltage of $4 \mathrm{~V}$. 
interval of $1 \mathrm{~nm}$, as shown in Fig. 2(a), setting the interface at HTL/EML to be 0 position.

As shown in Fig. 2(b), the yellow emission is strongest at the position of $11 \mathrm{~nm}$ from the interface between HTL/EML, and remains higher intensity distribution in the range of regions from 7 to $13 \mathrm{~nm}$. This implies that the exciton recombination zone in device B2 is close to the ETL side and its width is about $6 \mathrm{~nm}$, guaranteeing the effective emission of blue light in devices based on 4P-NPD : Bepp $_{2}$ as EML.

\subsection{Structure and performance of hybrid WOLEDs}

3.2.1 Structure and emission processes of hybrid WOLEDs. On the basis of the explored exciton distribution profile in the blue EML, and the motivation of design concept to achieve nearly $100 \%$ IQE, we fabricated hybrid WOLEDs (device W6) by adding a layer of doped yellow phosphor between HTL and blue EML and inserting an ultra-thin non-doped layer of green phosphor bis(2-phenylpyridinato- $N, \mathrm{C} 2)$ iridium(acetylacetonate) $\left(\operatorname{Ir}(\mathrm{ppy})_{2}(\mathrm{acac})\right)(0.4 \mathrm{~nm})$ located at $2 \mathrm{~nm}$ from the interface of $4 \mathrm{P}-\mathrm{NPD}: \mathrm{Bepp}_{2} / \mathrm{Bepp}_{2}$. Apart from varying the EML structure,

(a)

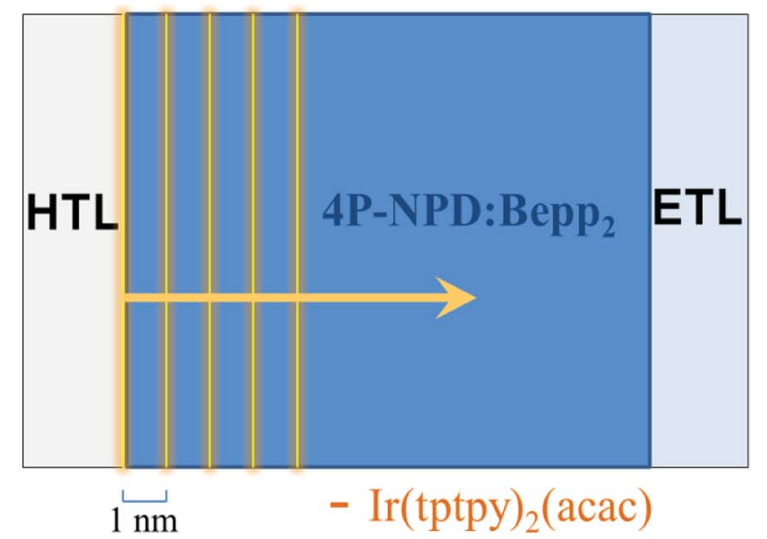

(b)

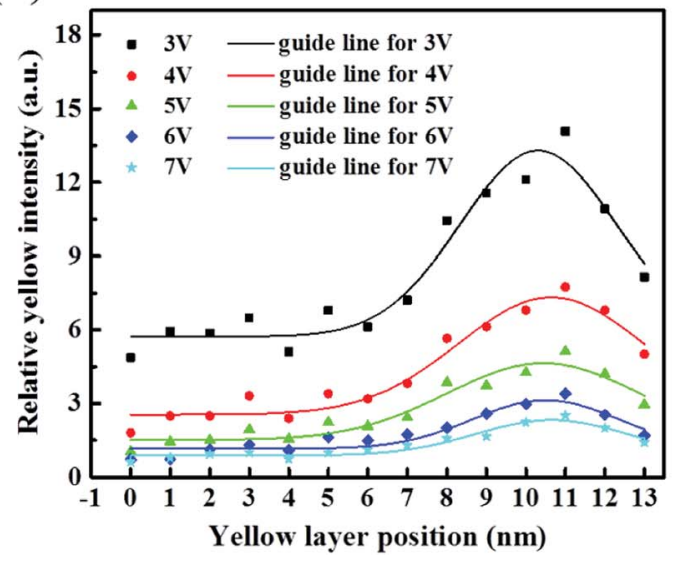

Fig. 2 (a) Schematic diagram of the exploration on exciton distribution in the blue EML. (b) Ratio of yellow emission peak intensity to blue intensity as a function of the position of a yellow ultra-thin layer in the EML at a driving voltage of 3-7 V. The solid lines are the guides of the corresponding data. all other parameters of the devices are kept unchanged to allow for optimum comparability. The optimized white device W6 structure is as follows: ITO/HATCN $(15 \mathrm{~nm}) /$ TAPC : HATCN $(4 / 2$, $95 \mathrm{~nm}) /$ TAPC $(40 \mathrm{~nm}) / 4 \mathrm{P}-\mathrm{NPD}: \operatorname{Ir}(\text { tptpy })_{2}$ (acac) $(4 \%, 5 \mathrm{~nm}) / 4 \mathrm{P}-$ NPD : $\operatorname{Bepp}_{2}(2: 1,13 \mathrm{~nm}) / \operatorname{Bepp}_{2}(2 \mathrm{~nm}) / \operatorname{Ir}(\text { ppy })_{2}($ acac $)(0.4 \mathrm{~nm}) /$ $\mathrm{Bepp}_{2}(3 \mathrm{~nm}) / \mathrm{Bepp}_{2}: \mathrm{Liq}(4.5 \%, 50 \mathrm{~nm}) / \mathrm{Liq}(1.25 \mathrm{~nm}) / \mathrm{Al}$. The schematic structure diagram of the processed hybrid WOLEDs and the chemical structures of the used phosphorescent materials are depicted in Fig. 3(a).

As given in Fig. 3(a), we rationally arranged the EML sequence to fabricate hybrid WOLEDs, thus enabled the device to achieve $100 \%$ IQE. In our proposed structure, as shown in Fig. 3(b), the exciton recombination region is strategically controlled in the blue EML, thus the singlet excitons produced from the exciton recombination region are mainly used for the blue light emission, and the triplets excitons transfer their energies to phosphorescent dyes for the yellow and green light emission.

Although 4P-NPD exhibits high PLQY, but its relatively low triplet state energy $(2.3 \mathrm{eV})$ compared to $\operatorname{Ir}(\mathrm{ppy})_{2}(\mathrm{acac})(2.4 \mathrm{eV})$ makes it not ideally located adjacent to $\operatorname{Ir}(\text { ppy })_{2}$ (acac) in hybrid WOLEDs. ${ }^{\mathbf{1 4 2 0}}$ This problem can be solved very well by inserting

\section{(a)}

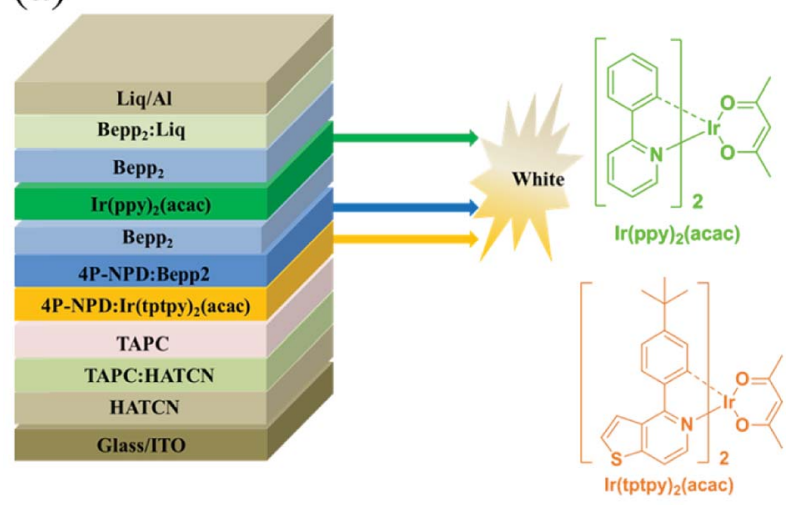

(b)

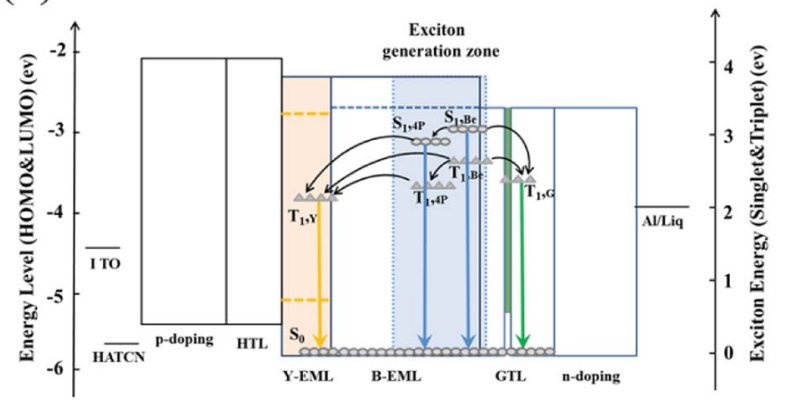

Fig. 3 (a) Schematic structure diagram of the processed hybrid WOLEDs and chemical structures of the used phosphorescent materials. (b) Energy level scheme of the resulting hybrid WOLEDs, and exciton $\left(S_{0}, S_{1}\right.$, and $\left.T_{1}\right)$ energy diagram in EMLs. The gray filled rectangle represents the main exciton generation zone. $Y, G, B, 4 P$ and $B e$ represents $\operatorname{Ir}(\text { tptpy })_{2}(\mathrm{acac}), \operatorname{Ir}(\mathrm{ppy})_{2}(\mathrm{acac}), 4 \mathrm{P}-\mathrm{NPD}$ and $\mathrm{Bepp}_{2}$, respectively. The solid lines and dashed lines correspond to HOMO and LUMO energy levels, respectively. The circles and rhombus refer to the exciton $\left(S_{0}, S_{1}\right.$, and $\left.T_{1}\right)$ energies, respectively. 
(a)

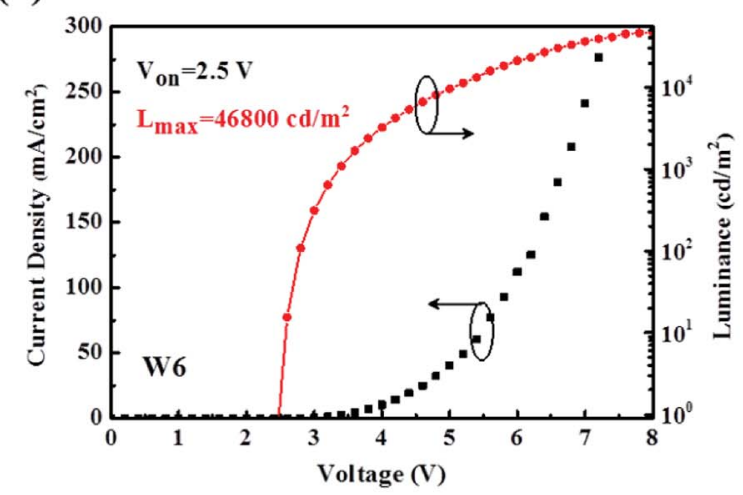

(c)

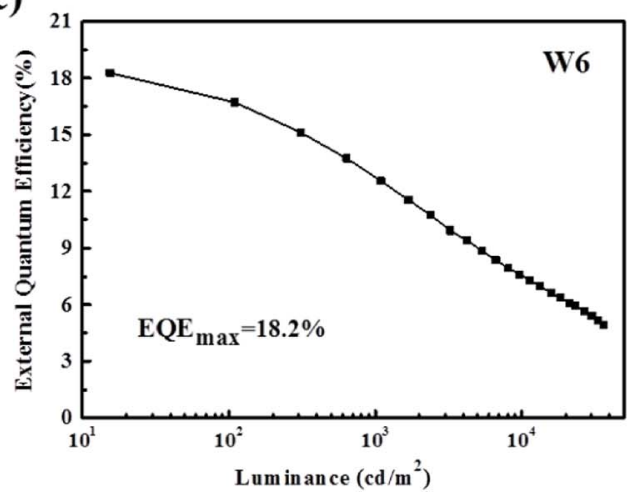

(b)

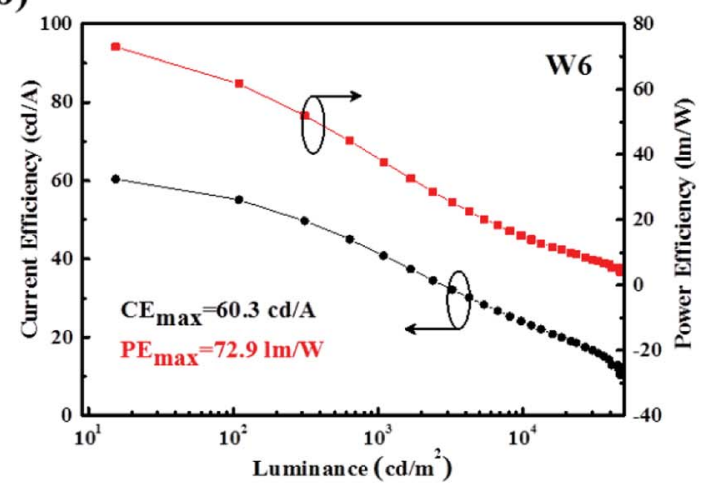

(d)

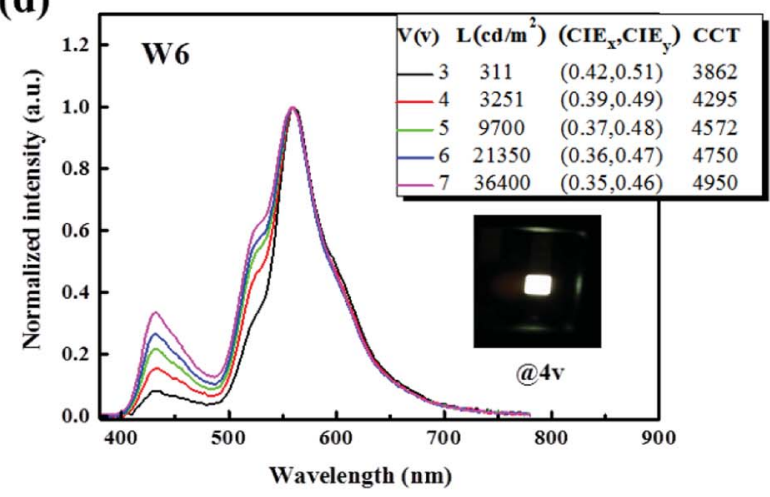

Fig. 4 (a) $J-L-V$ characteristics of the optimized device W6 with luminance measured in the forward direction without any out-coupling enhancement techniques. (b) CE-PE-L characteristics of device W6. (c) EQE-L characteristic of device W6. (d) Normalized EL spectra, luminance, CIE coordinates, and CCTs of device W6 at different voltages. The inset shows an EL emission photograph of device W6 at 4 V.

an additional organic layer with high triplet level between them, which can prevent the energy transfer of the triplet excitons from $\operatorname{Ir}(\mathrm{ppy})_{2}$ (acac) to 4P-NPD that causes unwanted energy loss. However, the use of the external interlayer has several disadvantages that limit the device quantum efficiency and power efficiency. First, the voltage drop across the interlayer is not negligible, leading to high voltage, thus low power efficiency. Furthermore, the interlayer maybe brings additional interfaces which inevitably increase the possibility of exciplex formation to some extent, impairing the efficiency of hybrid OLEDs. ${ }^{8}$ In our design, as shown in Fig. 3, we solved well this problem by simply introducing an ultra-thin green phosphor layer in Bepp 2 ETL far from the blue EML without changing the device structure. Thus, the $\mathrm{Bepp}_{2}$ layer effectively suppresses the energy loss from $\operatorname{Ir}(\mathrm{ppy})_{2}$ (acac) to 4P-NPD due to its higher triplet level (2.6 $\mathrm{eV})$. Importantly, the ultra-thin green phosphor layer can well regulate the triplet excitons in the blue EML by energy transfer, thus reduces the quenching caused by exciton accumulation, but does not affect the electron transport in devices. ${ }^{21-23}$

From the relationship of the triplet energy levels shown in Fig. 3(b), it is obvious that the triplet exciton energies on 4P$\mathrm{NPD}$ and $\mathrm{Bepp}_{2}$ can be well transferred to $\operatorname{Ir}(\text { tptpy })_{2}$ (acac), leading to the yellow emission. However, the singlet excitons in the blue EML can also directly transfer to $\operatorname{Ir}(\text { tptpy })_{2}$ (acac) molecules via Förster transfer, as a result, the blue emission in
WOLEDs will be greatly reduced, leading to the white emission not balanced. Considering the fact that the singlet exciton has a shorter diffusion length ${ }^{24}$ it provides a possibility to separate the singlet excitons spatially. As shown in Fig. 2(b) and 3(b), we effectively control the exciton recombination region in blue EML close to the ETL side, thus there is at least $5 \mathrm{~nm}$ separation distance to prevent the singlet excitons in blue EML from $\operatorname{Ir}(\text { tptpy })_{2}($ acac $)$ molecules, guaranteeing the enough blue emission. All in all, with such a working mechanism, all the generated excitons, both singlet and triplet excitons, can be fully utilized, realizing nearly $100 \%$ exciton harvesting while ensuring good white light emission.

3.2.2 Performance of hybrid WOLEDs. Based on the above strategies, high-performance hybrid WOLEDs can be expected. After the overall optimization of the structure parameters, the resulting WOLEDs show very impressive EL performances. The turn-on voltage of the optimized WOLED (device W6) is as low as $2.5 \mathrm{~V}$, as shown in Fig. 4(a), which should be mainly attributed to the "barrier-free" architecture that consists of the bipolar charge transporting ability of mixed fluorescent blue EML, where the charge carriers can be injected directly from the charge transport layer into EML without any obstacles. ${ }^{6}$

As shown in Fig. 4(b) and (c), the device W6 achieves a forward-viewing maximum power efficiency (PE), current efficiency (CE) and external quantum efficiency (EQE) of $72.9 \mathrm{~lm}$ 
Table 2 EL performances of some representative and our hybrid WOLEDs

\begin{tabular}{|c|c|c|c|c|c|}
\hline \multirow[b]{2}{*}{ Device } & \multirow[b]{2}{*}{$V_{\mathrm{on}}{ }^{a}(\mathrm{~V})$} & \multicolumn{3}{|c|}{ Max/@100 cd m ${ }^{-2} / @ 1000 \mathrm{~cd} \mathrm{~m}^{-2}$} & \multirow[b]{2}{*}{$\operatorname{CIE}^{b}(x, y)$} \\
\hline & & $\mathrm{CE}\left(\mathrm{cd} \mathrm{A}{ }^{-1}\right)$ & $\mathrm{PE}\left(\operatorname{lm~} \mathrm{W}^{-1}\right)$ & EQE $(\%)$ & \\
\hline Ref. 28 & 2.6 & $56.1 / 54.1 / 47.8$ & $62.9 / 60.4 / 41.7$ & $23.8 / 23.3 / 20.1$ & $(0.49,0.41)$ \\
\hline Ref. 29 & 2.9 & $49.4 /-1-$ & $53.5 /-1-$ & $19.0 /-1-$ & $(0.46,0.46)$ \\
\hline Ref. 30 & 3.1 & $-1-1-$ & $51.2 /-/ 38.7$ & $20.8 /-/ 19.6$ & $(0.39,0.45)$ \\
\hline Ref. 33 & 3.3 & $49.6 /-/ 49.5$ & $40.7 /-/ 37.1$ & $21.1 /-/ 20.0$ & $(0.43,0.43)$ \\
\hline Ref. 34 & 3.3 & $55.2 / 16.6 / 13.2$ & $49.6 / 25.7 / 9.0$ & $20.0 / 13.2 / 7.4$ & $(0.38,0.46)$ \\
\hline Ref. $35^{c}$ & 3.2 & $45.6 / 36.2 / 16.4$ & $35.8 / 21.6 / 6.9$ & $16.0 / 14.1 / 6.7$ & $(0.34,0.44)$ \\
\hline Ref. 36 & 3.2 & $56.0 /-/ 48.5$ & $55.5 /-/ 41.5$ & $19.3 /-/ 17.2$ & $(0.33,0.46)$ \\
\hline This work & 2.5 & $60.3 / 51.1 / 40.8$ & $72.9 / 61.7 / 37.7$ & $18.2 / 16.7 / 12.5$ & $(0.40,0.49)$ \\
\hline
\end{tabular}

${ }^{a}$ The turn-on voltage measured at $>1 \mathrm{~cd} \mathrm{~m}^{-2} \cdot{ }^{b}$ Measured at $1000 \mathrm{~cd} \mathrm{~m}^{-2} \cdot{ }^{c}$ Represents one all-phosphor devices.

$\mathrm{W}^{-1}, 60.3 \mathrm{~cd} \mathrm{~A}^{-1}$ and $18.2 \%$ without using light out-coupling technique, which decrease slightly to $61.7 \mathrm{~lm} \mathrm{~W}^{-1}, 51.1 \mathrm{~cd}$ $\mathrm{A}^{-1}$ and $16.7 \%$ at $100 \mathrm{~cd} \mathrm{~m}^{-2}$ and remain $44.1 \mathrm{~lm} \mathrm{~W}^{-1}, 45.0 \mathrm{~cd}$ $\mathrm{A}^{-1}$ and $13.7 \%$ at $500 \mathrm{~cd} \mathrm{~m}^{-2}$, respectively. It is worth mentioning that a forward-viewing maximum EQE of $18.2 \%$ is achieved at a current density of $0.025 \mathrm{~mA} \mathrm{~cm}^{-2}$, assuming an optical out coupling efficiency of roughly $21 \%$. This corresponds to an IQE close to unity, implying the full conversion of electrically generated excitons into light. The basic device performances are summarized in Table 2, where the performances of some reported hybrid WOLEDs are also given for comparison. It can be seen that our devices exhibit higher efficiencies, at a luminance of $1000 \mathrm{~cd} \mathrm{~m}^{-2}$, EQE, PE and CE are still as high as $12.5 \%, 37.7 \mathrm{~lm} \mathrm{~W}^{-1}$, and $40.8 \mathrm{~cd} \mathrm{~A}^{-1}$, which should be better results reported so far for hybrid WOLEDs.

As displayed in Fig. 4(d), device W6 emits good white light with three peaks, respectively, from the blue light of $4 \mathrm{P}$ NPD : Bepp $_{2}$, the green light of $\operatorname{Ir}(\mathrm{ppy})_{2}$ (acac) and the yellow light of $\operatorname{Ir}(\text { tptpy })_{2}$ (acac). The Commission Internationale de L'Eclairage (CIE) coordinates are shifted from $(0.42,0.51)$ to $(0.35,0.46)$ when the applied voltage is varied from 3 to $7 \mathrm{~V}$, which the homologous luminance increases from $311 \mathrm{~cd} \mathrm{~m}^{-2}$ to $36400 \mathrm{~cd} \mathrm{~m}^{-2}$. The corresponding correlated colour temperature (CCT) goes from $3862 \mathrm{~K}$ to $4950 \mathrm{~K}$. When the luminance is $1000 \mathrm{~cd} \mathrm{~m}^{-2}$, the CCT is around $4000 \mathrm{~K}$ very close to the warm white illumination, meeting the requirement of indoor lighting. These performances are comparable to or even higher than those of all phosphor-doped WOLEDs reported before..$^{25-27}$

3.2.3 Detailed analysis on operational mechanism of hybrid WOL-EDs

I. Effect of $4 P-N P D$ and Bepp 2 ratio. From the previous section, we know that the optimum ratio of $4 \mathrm{P}-\mathrm{NPD}$ and $\mathrm{Bepp}_{2}$ in blue OLEDs is confirmed to be $2: 1$. In order to explore the ratio influence in the hybrid WOLEDs, we have made a comparison device with structure of ITO/HAT-CN $(15 \mathrm{~nm}) /$ TAPC : HAT-CN (4/2, $95 \mathrm{~nm}) /$ TAPC $(40 \mathrm{~nm}) / 4 \mathrm{P}-\mathrm{NPD}: \operatorname{Ir}(\text { tptpy })_{2}(-$ acac) $(4 \%, 5 \mathrm{~nm}) / 4 \mathrm{P}-\mathrm{NPD}: \mathrm{Bepp}_{2}(X, 13 \mathrm{~nm}) / \mathrm{Bepp}_{2}(2 \mathrm{~nm}) /$ $\operatorname{Ir}(\mathrm{ppy})_{2}(\mathrm{acac})(0.4 \mathrm{~nm}) / \mathrm{Bepp}_{2}(3 \mathrm{~nm}) / \mathrm{Bepp}_{2}: \mathrm{Liq}(4.5 \%, 50 \mathrm{~nm}) /$
Liq $(1.25 \mathrm{~nm}) / \mathrm{Al}, X=1: 1$, refer to device W1. As depicted in Fig. 5(a), the efficiency of two devices is different under low voltage. The efficiency of device W6 is higher than that of device W1. Although there is little difference in their efficiency at high voltage, as portrayed in Fig. 5(b), where the normalized EL

\section{(a)}

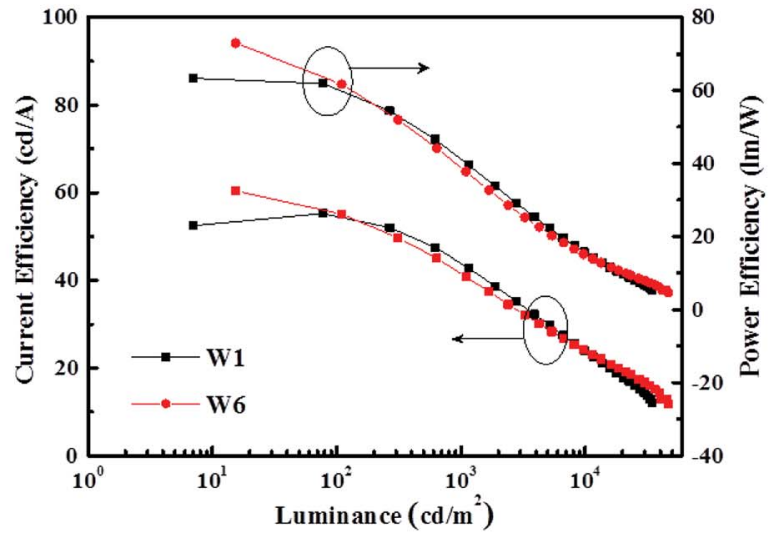

(b)

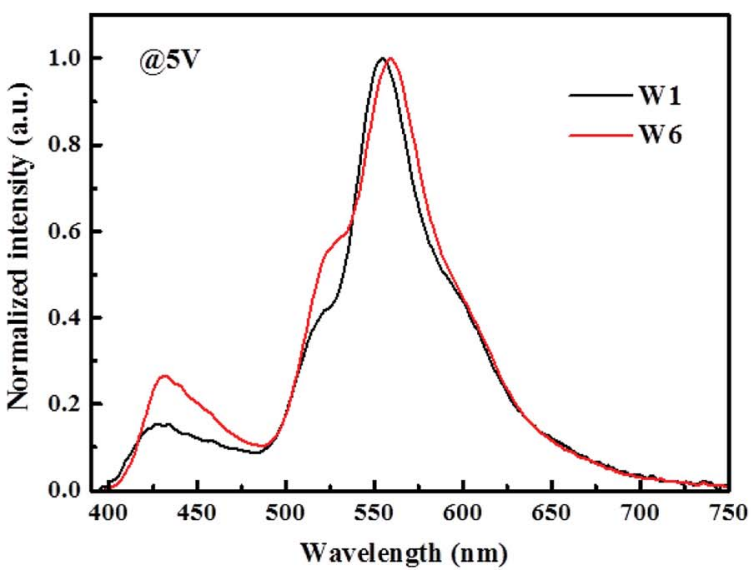

Fig. 5 (a) CE-PE-L characteristics of device W1 and W6. (b) Normalized EL spectra of device W1 and W6 at $5 \mathrm{~V}$. 


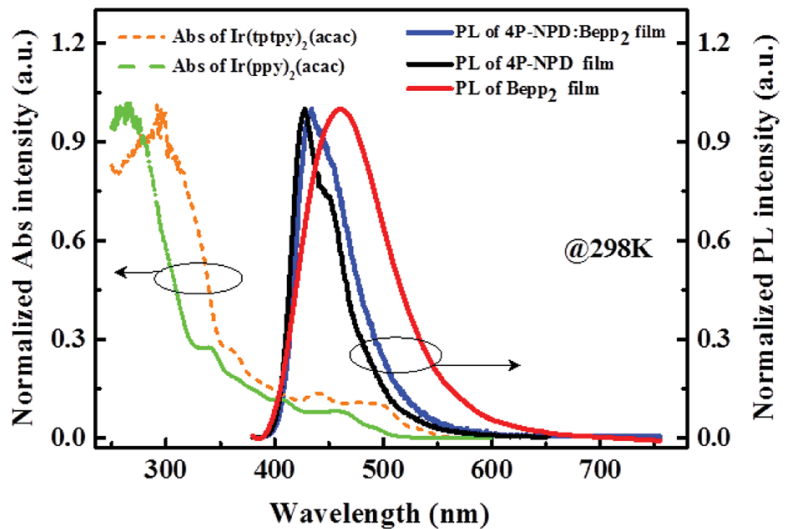

Fig. 6 Normalized absorption spectra of $\operatorname{Ir}(\mathrm{ppy})_{2}(\mathrm{acac})$ and Ir(tptpy) $)_{2}$ (acac) measured in $\mathrm{CH}_{2} \mathrm{Cl}_{2}$ solvent as well as photoluminescence spectra of pure 4P-NPD, pure $\mathrm{Bepp}_{2}$, and 4PNPD : $\operatorname{Bepp}_{2}(2: 1)$ mixture solid films.

spectra of device W1 and W6 are given, device W1 emits lower blue and green light intensity with respect to device W6, which should be necessary for a good white light emission.

II. Emission mechanism of phosphors. As shown in Fig. 6, there is a large overlap between the absorption spectra of $\operatorname{Ir}(\mathrm{ppy})_{2}$ (acac), $\operatorname{Ir}$ (tptpy $)_{2}$ (acac) and the emission spectra of $4 \mathrm{P}$ -

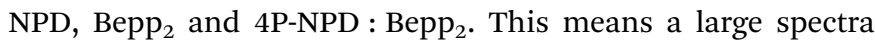
overlap between the fluorescence band of the ligand-centered singlet $\left({ }^{1} \mathrm{LC}\right)$ states in $4 \mathrm{P}-\mathrm{NPD}$ and the absorption bands of both metal ligand charge transfer singlet $\left({ }^{1} \mathrm{MLCT}\right)$ and triplet $\left({ }^{3}\right.$ MLCT $)$ states in $\operatorname{Ir}(\text { ppy })_{2}$ (acac) and $\operatorname{Ir}(\text { tptpy })_{2}$ (acac). As a result, the lowest singlet-excited states $\left(\mathrm{S}_{1}\right)$ in $4 \mathrm{P}-\mathrm{NPD}$ can be energetically transferred to either the lowest triplet-excited states $\left(\mathrm{T}_{1}\right)$ or the $S_{1}$ (which then transits to the $T_{1}$ via rapid intersystem crossing (ISC) for the strong spin-orbit coupling) in $\operatorname{Ir}(\mathrm{ppy})_{2}(-$ acac) and $\operatorname{Ir}(\text { tptpy })_{2}$ (acac) by Förster energy transfer (Coulomb interaction). ${ }^{23,37}$ Furthermore, according to the previous reports, ${ }^{15,16,38}$ the $\mathrm{T}_{1}$ values of $4 \mathrm{P}-\mathrm{NPD}$ and $\mathrm{Bepp}_{2}$ are $2.3 \mathrm{eV}$ and $2.6 \mathrm{eV}$ respectively, and the $\mathrm{T}_{1}$ values of $\operatorname{Ir}(\mathrm{ppy})_{2}$ (acac) and $\operatorname{Ir}(\text { tptpy })_{2}$ (acac) are $2.4 \mathrm{eV}$ and $2.2 \mathrm{eV}$, thus ensuring the efficient $\mathrm{T}_{1}\left(\right.$ Bepp $\left._{2}\right) \rightarrow \mathrm{T}_{1}\left(\operatorname{Ir}(\mathrm{ppy})_{2}\right.$ (acac) and $\operatorname{Ir}(\text { tptpy })_{2}$ (acac)) transition and $\mathrm{T}_{1}$ (4P-NPD) $\rightarrow \mathrm{T}_{1}\left(\operatorname{Ir}(\text { tptpy })_{2}\right.$ (acac)) transition through a Dexter-type (electron-exchange) interaction because of their $\mathrm{T}_{1}$ energy level difference. In addition, the PL spectra show that 4PNPD : Bepp 2 film does not show a long wavelength emission, excluding the possibility of exciplex formation in our material system. As shown in Fig. 6, the blue emission of 4P-NPD : Bepp 2 blend film is obviously from the co-emission of 4P-NPD and Bepp $_{2}$, which is the special point in our devices.

In order to further confirm the Förster energy transfer between fluorophors and phosphors, we tested the PL transient decay lifetime of blue fluorescence in three different films. As shown in Fig. 7, where the PL transient decay curves of the $4 \mathrm{P}$ NPD : Bepp $_{2}$ mixed films with or without phosphorescent layer are given. Clearly, the blue lifetime is obviously decreased from $1.05 \mathrm{~ns}$ of film $\mathrm{T}_{1}$ to $0.95 \mathrm{~ns}$ of film $\mathrm{T}_{2}$, and to $0.53 \mathrm{~ns}$ of film $\mathrm{T}_{3}$. As known to all, under PL excitation, the formation of excitons is only singlet states. The lifetime reduction of the blue

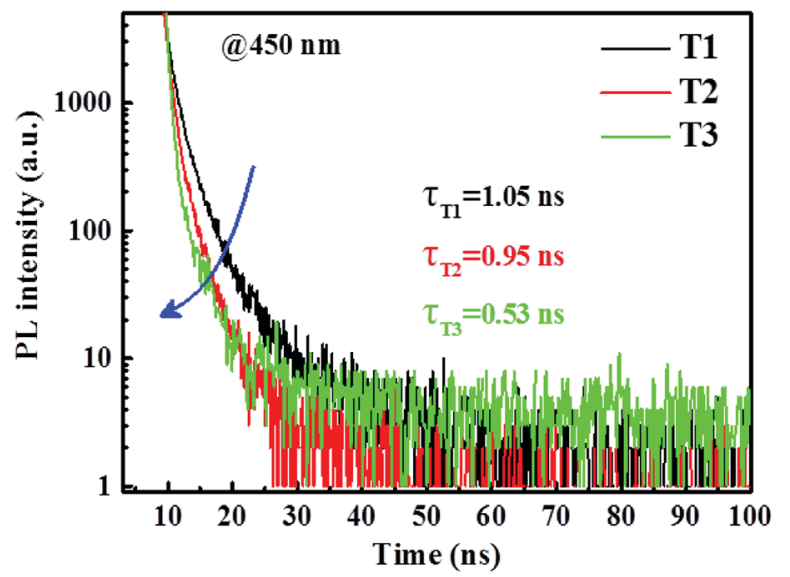

Fig. $7 \mathrm{PL}$ transient decay curves of three different films tested at $450 \mathrm{~nm}$ ( $P L$ emission peak of Bepp 2 ). Related film structures are as follows: film $\mathrm{T}_{1}$ : 4P-NPD (5 nm)/4P-NPD : $\operatorname{Bepp}_{2}(2: 1,13 \mathrm{~nm}) / \mathrm{Bepp}_{2}$ $(2 \mathrm{~nm})$, film $\mathrm{T}_{2}: 4 \mathrm{P}-\mathrm{NPD}: \operatorname{Ir}(\text { tptpy })_{2}$ (acac) $(4 \%, 5 \mathrm{~nm}) / 4 \mathrm{P}-\mathrm{NPD}: \mathrm{Bepp}_{2}$ (2 : 1, $13 \mathrm{~nm}) /$ Bepp $_{2}(2 \mathrm{~nm})$, film $\mathrm{T}_{3}: 4 \mathrm{P}-\mathrm{NPD}(5 \mathrm{~nm}) / 4 \mathrm{P}-\mathrm{NPD}: \mathrm{Bepp}_{2}$ $(2: 1,13 \mathrm{~nm}) / \operatorname{Bepp}_{2}(2 \mathrm{~nm}) / \operatorname{Ir}(\text { ppy })_{2}($ acac $)(0.4 \mathrm{~nm})$.

emission when adding phosphorescent layer means the Förster energy transfer from the singlet states of $4 \mathrm{P}-\mathrm{NPD}$ and Bepp 2 to the triplet states of phosphors $\operatorname{Ir}(\mathrm{ppy})_{2}$ (acac) and $\operatorname{Ir}(\text { tptpy })_{2}$ (acac) and the green $\operatorname{Ir}(\mathrm{ppy})_{2}$ (acac) molecules obtain more energies.

It is widely believed that the emitting light mechanisms in doped OLEDs include the direct recombination of carriers and energy transfer. In order to further explore the mechanism of yellow light in our hybrid WOLEDs, the hole-only and electrononly devices were fabricated. Their $J-V$ characteristics are shown

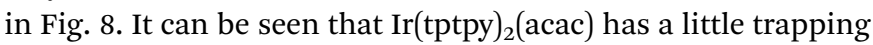
effect on the holes, whereas the capture of electrons is almost negligible. This also means that the yellow emission is indeed energy transfer processes, and mainly the Dexter energy transfer from the triplet states of $4 \mathrm{P}-\mathrm{NPD}$ and $\mathrm{Bepp}_{2}$ to the triplet states

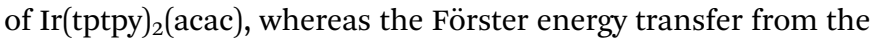
singlet states of 4 P-NPD to the triplet states of $\operatorname{Ir}(\text { tptpy })_{2}$ (acac) is almost negligible. To verify this assumption, we made the devices with different $4 \mathrm{P}-\mathrm{NPD}: \mathrm{Bepp}_{2}$ thicknesses according to the different diffusion distances of singlet and triplet excitons.

As shown in Fig. 9, we can find that the blue light intensity becomes very weak when the thickness is less than $7 \mathrm{~nm}$, indicating the strong Förster energy transfer from 4P-NPD and $\operatorname{Ir}(\text { tptpy })_{2}$ (acac). When the blue EML thickness is over $13 \mathrm{~nm}$, the blue intensity varies with the thickness, indicating that the Förster energy transfer between 4 P-NPD and $\operatorname{Ir}(\text { tptpy })_{2}$ (acac) is negligible. Therefore, it is concluded that the yellow light emission in our hybrid WOLEDs is mainly attributed to the Dexter energy transfer from $4 \mathrm{P}-\mathrm{NPD}$ and $\mathrm{Bepp}_{2}$ to $\operatorname{Ir}(\text { tptpy })_{2}$ (acac).

For the emission of the ultra-thin phosphor, there are a lot of literatures about WOLEDs that prove to be only energy transfer. $^{\mathbf{1 2 , 3 9}}$ In order to demonstrate the emission process of the ultra-thin green phosphor in our hybrid WOLEDs, we have made a device $\mathrm{W} 2$ without the ultra-thin green phosphor for comparison. The device W2 structure is ITO/HAT-CN (15 nm)/ 
(a)

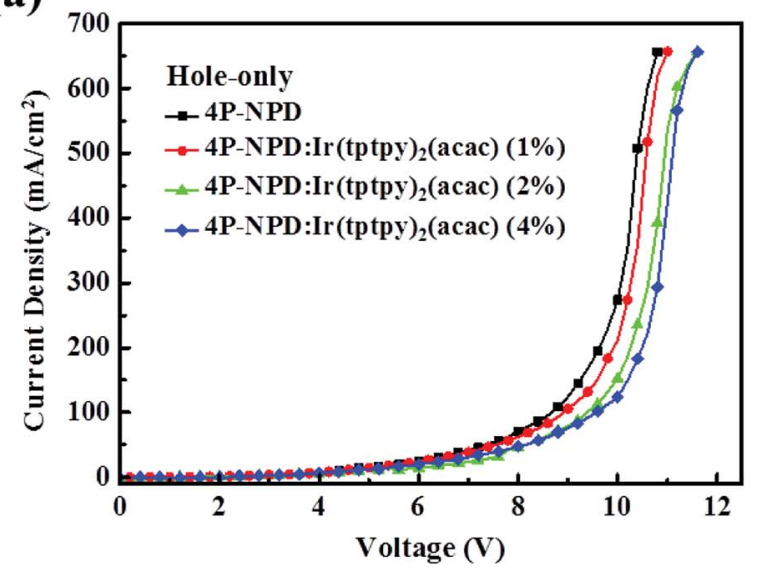

(b)

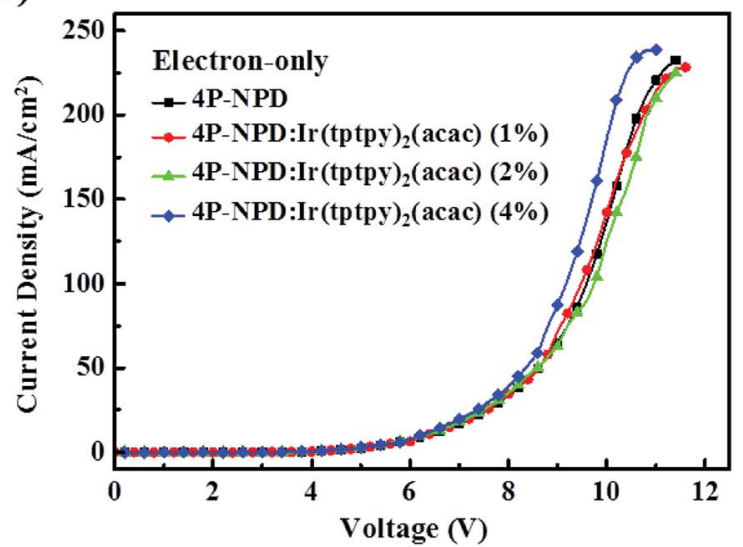

Fig. 8 Current density-voltage $(J-V)$ characteristics of (a) hole-only devices: ITO/HAT-CN (15 nm)/TAPC : HAT-CN (4/2, $95 \mathrm{~nm}) / T A P C ~(40$ $\mathrm{nm}) / 4 \mathrm{P}-\mathrm{NPD}: \operatorname{Ir}(\text { tptpy })_{2}$ (acac) $(X=0,1,2,4 \%, 5 \mathrm{~nm}) / 4 \mathrm{P}-\mathrm{NPD}: \mathrm{Bepp}_{2}$ (2 : $1,13 \mathrm{~nm}) /$ TAPC $(40 \mathrm{~nm}) /$ TAPC : HAT-CN $(4 / 2,95 \mathrm{~nm}) / \mathrm{HAT}-\mathrm{CN}(15$ $\mathrm{nm}) / \mathrm{Al}$, and (b) electron-only devices: ITO/Liq $(1.25 \mathrm{~nm}) / \mathrm{Bepp}_{2}$ (50 $\mathrm{nm}) / 4 \mathrm{P}-\mathrm{NPD}: \operatorname{Ir}(\text { tptpy })_{2}$ (acac) $(X=0,1,2,4 \%, 5 \mathrm{~nm}) / 4 \mathrm{P}-\mathrm{NPD}: \mathrm{Bepp}_{2}$ $(2: 1,13 \mathrm{~nm}) / \mathrm{Bepp}_{2}(40 \mathrm{~nm}) / \mathrm{Liq}(1.25 \mathrm{~nm}) / \mathrm{Al}$.

TAPC : HAT-CN (4/2, $95 \mathrm{~nm}) /$ TAPC $(40 \mathrm{~nm}) / 4 \mathrm{P}-\mathrm{NPD}: \operatorname{Ir}(\text { tptpy })_{2}(-$ acac) $(4 \%, 5 \mathrm{~nm}) / 4 \mathrm{P}-\mathrm{NPD}: \mathrm{Bepp}_{2}(2: 1,13 \mathrm{~nm}) / \mathrm{Bepp}_{2}(5 \mathrm{~nm}) /$ $\mathrm{Bepp}_{2}: \mathrm{Liq}(4.5 \%, 50 \mathrm{~nm}) / \mathrm{Liq}(1.25 \mathrm{~nm}) / \mathrm{Al}$. It can be seen from the $J-V$ characteristics of device $\mathrm{W} 2$ and W6 in Fig. 10 that there is no obvious differences between two devices, excluding the existence of charge carrier trapping on green phosphor. This also means that the green emission from $\operatorname{Ir}(\mathrm{ppy})_{2}$ (acac) molecules is also energy transfer.

3.2.4 Role of ultra-thin green phosphor layer. As we see, the incorporated $0.4 \mathrm{~nm}$ green ultrathin emitting layer also plays an important role in improving efficiency and efficiency roll-off. To examine its role, we made the device $\mathrm{W} 2$ without the ultrathin green EML as contrast to the optimism device W6. The device W2(Y/B) configuration is as follows: ITO/HATCN (15 nm)/TAPC : HAT-CN (4/2, $95 \mathrm{~nm}) /$ TAPC $(40 \mathrm{~nm}) / 4 \mathrm{P}-$ NPD:Ir(tptpy $)_{2}$ (acac) $(4 \%, 5 \mathrm{~nm}) / 4 \mathrm{P}-\mathrm{NPD}: \mathrm{Bepp}_{2}(2: 1,13 \mathrm{~nm}) /$ Bepp $_{2}(5 \mathrm{~nm}) /$ Bepp $_{2}: \operatorname{Liq}(4.5 \%, 50 \mathrm{~nm}) / \mathrm{Liq}(1.25 \mathrm{~nm}) / \mathrm{Al}$.

As displayed in Fig. 11(a) and (b), we can find that the introduction of the ultrathin green EML not only greatly

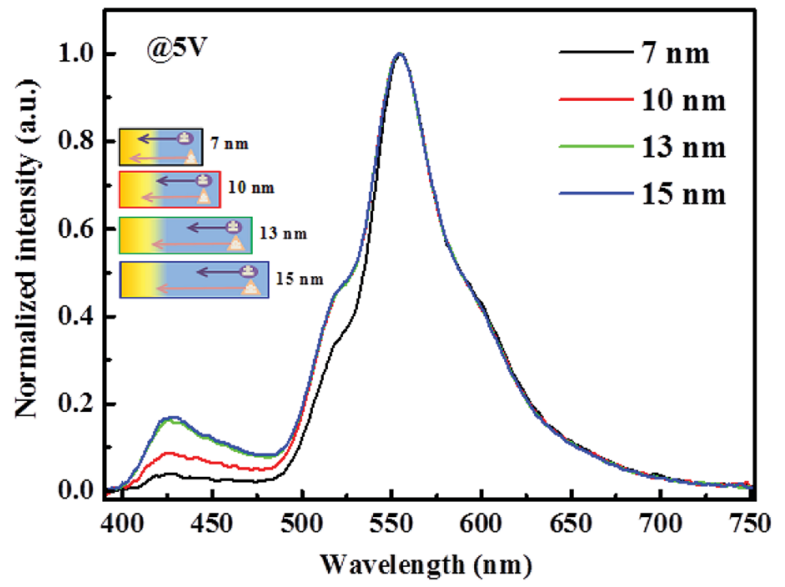

Fig. 9 Normalized EL spectra of devices with different blue EML thicknesses of 5, 10,13 and $15 \mathrm{~nm}$. The device structure is ITO/HATCN (15 nm)/TAPC: HAT-CN (4/2, $95 \mathrm{~nm}) /$ TAPC $(40 \mathrm{~nm}) / 4 \mathrm{P}-$ NPD:Ir(tptpy) ${ }_{2}$ (acac) $(4 \%, 5 \mathrm{~nm}) / 4 \mathrm{P}-\mathrm{NPD}: \mathrm{Bepp}_{2}(2: 1, X \mathrm{~nm}) / \mathrm{Bepp}_{2}(2$ $\mathrm{nm}) / \mathrm{Ir}(\mathrm{ppy})_{2}$ (acac) $(0.4 \mathrm{~nm}) /$ Bepp $_{2}(3 \mathrm{~nm}) /$ Bepp $_{2}$ :Liq $(4.5 \%, 50 \mathrm{~nm}) / \mathrm{Liq}$ $(1.25 \mathrm{~nm}) / \mathrm{Al}$. The inset marks the different diffusion lengths of $S_{1}$ and $T_{1}$ excitons.

enhances the efficiency, but also significantly improves the efficiency roll-off at high luminance. This can also be explained from the EL spectra shown in Fig. 11(c), the inserted ultrathin green EML absorbed partial exciton energies in blue EML, resulting in the green emission, and the reduction of the blue emission in device W6. This process should be very favor in reducing the quenching caused by exciton aggregation. For comparison purposes and clarity, the EL performances of devices W1, W2 and W6 are shown in Table S1. $\dagger$

3.2.5 Quenching mechanism in device W6. As we know, the efficiency roll-off is a common problem in OLEDs, which may limit their implementation at high luminance. Generally, triplet-triplet annihilation (TTA), triplet-polaron quenching (TPQ) and field-induced quenching are possible quenching processes in OLEDs. ${ }^{40}$ For TTA model, as reported by Baldo et al. ${ }^{40}$ the EQE $(\eta)$ dependence of current density $(J)$ can be expressed as follows,

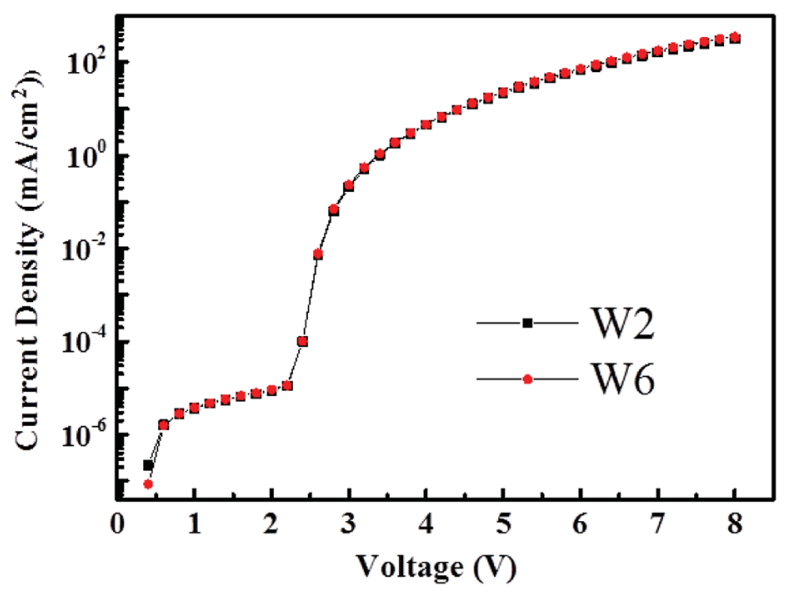

Fig. $10 \mathrm{~J}-\mathrm{V}$ characteristics of device W2 and W6. 
(a)

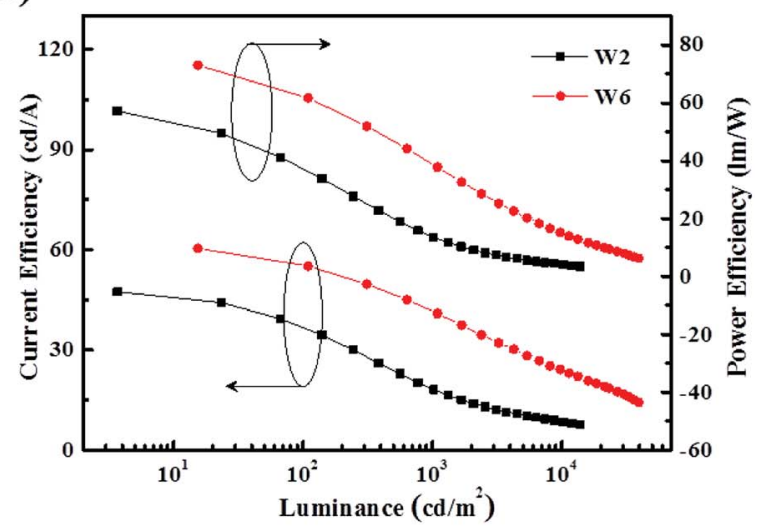

(b)

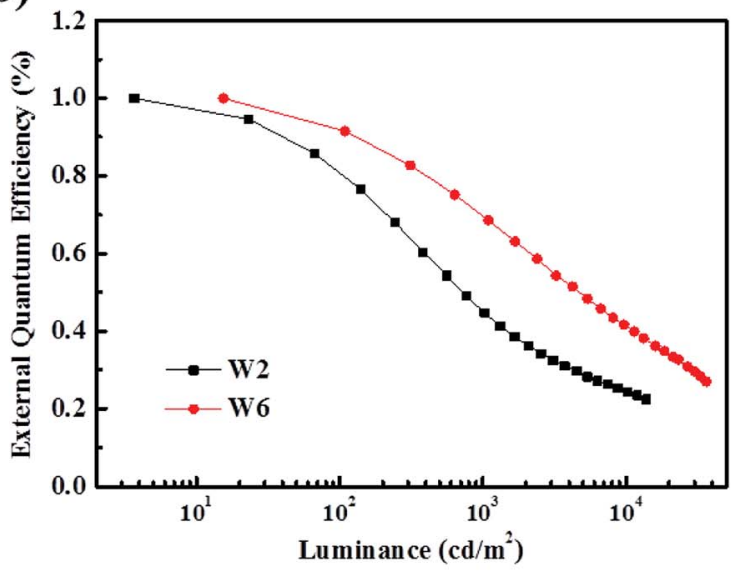

(c)

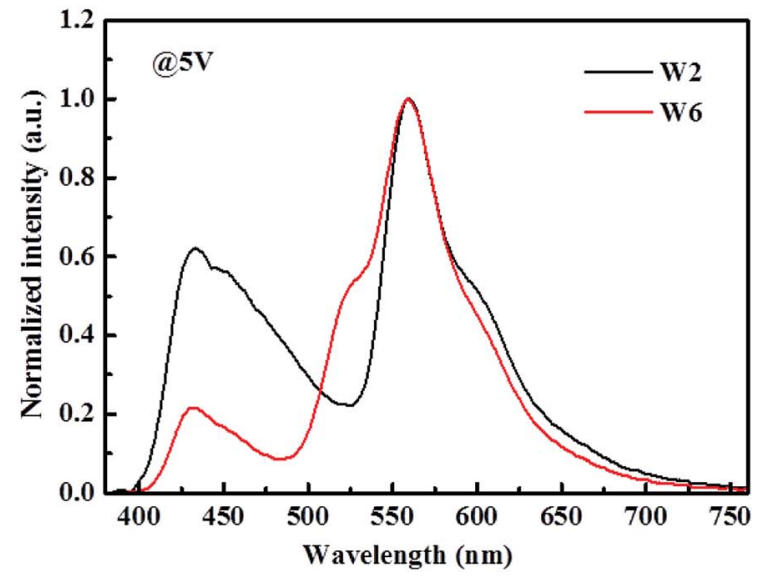

Fig. 11 (a) CE-PE-L characteristics of device W2 and W6. (b) Normalized EQE-L characteristics of device W2 and W6. (c) Normalized EL spectra of device W2 and W6.

$$
\frac{\eta_{T T}}{\eta_{0}}=\frac{J_{0}}{4 J}\left(\sqrt{1+8 \frac{J}{J_{0}}}-1\right)
$$

While for TPQ model, the expression can be described by S. Reineke et al. ${ }^{41}$

$$
\frac{\eta_{\mathrm{TP}}}{\eta_{0}}=\frac{1}{1+\left(\tau K_{\mathrm{TP}} C J\right)^{1 /(1+l)}}
$$

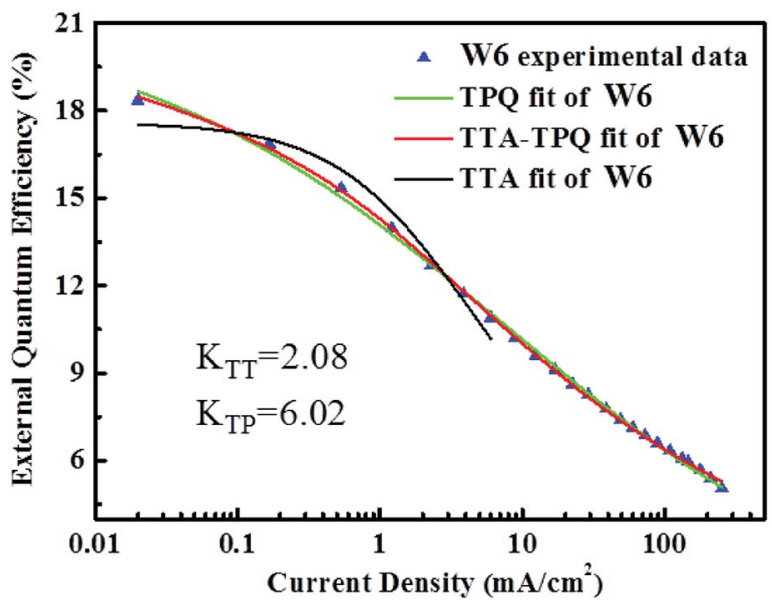

Fig. 12 EQE-J dependence of device W6. The green line refers to the TPQ fitting curve and the red line refers to the TTA-TPQ fitting curve. The black line refers to the TTA fitting curve.

Here $\eta_{0}$ is the EQE without the triplet exciton quenching, and $J_{0}$ is the critical current density at $\eta=\eta_{0} / 2, \tau$ is the decay lifetime of the triplet, $C$ is a constant related to the parameters such as the dielectric constant and carrier mobility, $K_{\mathrm{TP}}$ is the TPQ rate constant, 1 is taken to be unity. The unified model proposed by S. Reineke et $a l^{41}$ incorporates the TTA and TPQ quenching mechanisms, which is given as follows,

$$
\begin{aligned}
\frac{\eta_{\mathrm{EQE}}}{\eta_{0}}= & \frac{e W}{\tau J}\left(\sqrt{\frac{\left(\frac{1}{\tau}+\left(\tau K_{\mathrm{TP}} C J\right)^{1 /(1+l)}\right)^{2}+\frac{2 J}{e W} K_{\mathrm{TT}}}{K_{\mathrm{TT}}^{2}}}\right. \\
& \left.-\frac{\frac{1}{\tau}+K_{T P} C J^{1 /(1+l)}}{K_{\mathrm{TT}}}\right)
\end{aligned}
$$

where $W$ represents the width of exciton recombination zone, $K_{\mathrm{TT}}$ is the TTA rate constant, the other parameters are the same as the mentioned above. The EQE of devices W6 as a function of current density and the fitting according to the unified model (red line) integrating the TTA with TPQ mechanism are shown in Fig. 12. It is demonstrated that our experimental data can be well fitted by TTA-TPQ model.

As shown in Fig. 12, our experimental data can be well fitted by TPQ model in high brightness, and there is no obvious difference between TPQ model and TTA-TPQ model, which indicating that the TPQ process is the main reason for the efficiency roll-off at high luminance in our devices. $K_{\mathrm{TT}}(\approx 2.08)$ is much lower than $K_{\mathrm{TP}}(\approx 6.02)$, which indicates that the efficiency roll-off at high luminance in device W6 is mainly due to the triplet-polaron quenching. The failure of TTA model fitting implies that the wide exciton recombination zone (as shown in Fig. 2) conduces the decrease of triplet exciton concentration, thus reducing the TTA effect and finally resulting in the reduced efficiency roll-off. The good TPQ model fitting implies that there exist unbalanced charge injection and transport in our devices, leading to severe charge accumulation, thus quenching emissive excitons. 


\section{Conclusions}

We have successfully achieved high-performance hybrid WOLEDs by simply and effective exciton regulation emissive layer structure. It can be seen that the strategic introduction of an ultra-thin green phosphor EML in proper location in ETL not only greatly enhances the efficiency, but also significantly improves the efficiency roll-off at high luminance, which is attributed to the efficient regulation in the emissive excitons.

This strategy has rendered a record maximum forward viewing external quantum efficiency and power efficiency of $18.2 \%$ and $72.9 \mathrm{~lm} \mathrm{~W}^{-1}$, and they are as high as $16.7 \%$ and 61.7 $\operatorname{lm~} \mathrm{W}^{-1}$ at $100 \mathrm{~cd} \mathrm{~m}^{-2}$, and $12.5 \%$ and $37.7 \mathrm{~lm} \mathrm{~W}^{-1}$ at $1000 \mathrm{~cd}$ $\mathrm{m}^{-2}$, respectively, in our hybrid WOLEDs without any outcoupling assistance. Such productive results indicate a promising way to promote the development of high-performance hybrid WOLEDs by simple structure, which is very valuable for the further design of high-performance WOLEDs in the future.

\section{Conflicts of interest}

There are no conflicts to declare.

\section{Acknowledgements}

The authors gratefully acknowledge the National Natural Science Foundation of China (21788102, 51333007, 91433201, 11661131001) and Guangzhou science \& technology plan project (201707020040) for the support of this research.

\section{References}

1 C. W. Tang and S. A. Vanslyke, Appl. Phys. Lett., 1987, 51, 913. 2 J. Kido, K. Hongawa, K. Okuyama and K. Nagai, Appl. Phys. Lett., 1994, 64, 815.

3 Y. R. Sun, N. C. Giebink, H. Kanno, B. W. Ma, M. E. Thompson and S. R. Forrest, Nature, 2006, 440, 908.

4 L. Ding, Y. Q. Sun, H. Chen, F. S. Zu, Z. K. Wang and L. S. Liao, J. Mater. Chem. C, 2014, 2, 10403.

5 C. L. Liu, C. J. Zheng, X. K. Liu, Z. Chen, J. P. Yang, F. Li, X. M. Ou and X. H. Zhang, J. Mater. Chem. C, 2015, 3, 1068.

6 J. Ye, C. J. Zheng, X. M. Ou, X. H. Zhang, M. K. Fung and C. S. Lee, Adv. Mater., 2012, 24, 3410.

7 C. J. Zheng, J. Wang, J. Ye, M. F. Lo, X. K. Liu, M. K. Fung, X. H. Zhang and C. S. Lee, Adv. Mater., 2013, 25, 2205.

8 G. Schwartz, S. Reineke, T. C. Rosenow, K. Walzer and K. Leo, Adv. Funct. Mater., 2009, 19, 1319.

9 T. Peng, Y. Yang, H. Bi, Y. Liu, Z. Hou and Y. Wang, J. Mater. Chem., 2011, 21, 3551.

10 S. Hofmann, M. Furno, B. Lüssem, K. Leo and M. C Gather, Phys. Status Solidi A, 2013, 210, 1467.

11 B. Liu, D. Luo, J. Zou, D. Gao, H. Ning, L. Wang, J. Peng and Y. Cao, J. Mater. Chem. C, 2015, 3, 6359.

12 J. Wang, J. Chen, X. Qiao, S. M. Alshehri, T. Aharnad and D. Ma, ACS Appl. Mater. Interfaces, 2016, 8, 10093.
13 Y. Q. Li, Y. Liu, W. M. Bu, D. Lu, Y. Wu and Y. Wang, Chem. Mater., 2000, 12, 2672.

14 G. Schwartz, M. Pfeiffer, S. Reineke, K. Walzer and K. Leo, Adv. Mater., 2007, 19, 3672.

15 Y. Liu, F. Liang, L. S. Cui, X. B. Shi, Z. K. Wang and L. S. Liao, Adv. Opt. Mater., 2016, 4, 2051.

16 Y. Miao, K. Wang, L. Gao, B. Zhao, Z. Wang, Y. Zhao, A. Zhang, H. Wang, Y. Hao and B. Xu, J. Mater. Chem. C, 2018, 6, 1853.

17 B. Liu, X. L. Li, H. Tao, J. Zou, M. Xu, L. Wang, J. Peng and Y. Cao, J. Mater. Chem. C, 2017, 5, 7668.

18 B. Liu, H. Nie, G. Lin, S. Hu, D. Gao, J. Zou, M. Xu, L. Wang, Z. Zhao, H. Ning, J. Peng, Y. Cao and B. Z. Tang, ACS Appl. Mater. Interfaces, 2017, 9, 34162.

19 A. Salehi, S. Ho, Y. Chen, C. Peng, H. Yersin and F. So, Adv. Opt. Mater., 2017, 5, 1700197.

20 T. Tsuzuki and S. Tokito, Adv. Mater., 2007, 19, 276.

21 S. H. Li, S. F. Wu, Y. K. Wang, J. J. Liang, Q. Sun, C. C. Huang, J. C. Wu, L. S. Liao and M. K. Fung, J. Mater. Chem. C, 2018, 6, 342.

22 D. Xia, B. Wang, B. Chen, S. Wang, B. Zhang, J. Ding, L. Wang, X. Jing and F. Wang, Angew. Chem., Int. Ed., 2014, 53, 1048.

23 Q. Wang, I. W. H. Oswald, X. Yang, G. Zhou, H. Jia, Q. Qiao, Y. Chen, J. Hoshikawa-Halbert and B. E. Gnade, Adv. Mater., 2014, 26, 8107.

24 M. A. Baldo, D. F. O'Brien, M. E. Thompson and S. R. Forrest, Phys. Rev. B: Condens. Matter Mater. Phys., 1999, 60, 14422.

25 S. J. Su, T. Chiba, T. Takeda and J. Kido, Adv. Mater., 2008, 20, 2125.

26 S. Gong, Y. Chen, C. Yang, C. Zhong, J. Qin and D. Ma, Adv. Mater., 2010, 22, 5370.

27 L. Duan, D. Zhang, K. Wu, X. Huang, L. Wang and Y. Qiu, Adv. Funct. Mater., 2011, 21, 3540.

28 X. Ouyang, X. L. Li, L. Ai, D. Mi, Z. Ge and S. J. Su, ACS Appl. Mater. Interfaces, 2015, 7, 7869.

29 X. Du, G. Li, J. Zhao, S. Tao, C. Zheng, H. Lin, Q. Tong and X. Zhang, Adv. Opt. Mater., 2017, 5, 1700498.

30 D. Zhang, M. Cai, Y. Zhang, D. Zhang and L. Duan, ACS Appl. Mater. Interfaces, 2015, 7, 28693.

31 N. Sun, Q. Wang, Y. Zhao, Y. Chen, D. Yang, F. Zhao, J. Chen and D. Ma, Adv. Mater., 2014, 26, 1617.

32 Z. Chen, X. K. Liu, C. J. Zheng, J. Ye, C. L. Liu, F. Li, X. M. Ou, C. S. Lee and X. H. Zhang, Chem. Mater., 2015, 27, 5206.

33 N. Sun, Q. Wang, Y. Zhao, D. Yang, F. Zhao, J. Chen and D. Ma, J. Mater. Chem. C, 2014, 2, 7494.

34 X. Du, J. Zhao, S. Yuan, C. Zheng, H. Lin, S. Tao and C. S. Lee, J. Mater. Chem. C, 2016, 4, 5907.

35 S. L. Lai, W. Y. Tong, S. C. F. Kui, M. Y. Chan, C. C. Kwok and C. M. Che, Adv. Funct. Mater., 2013, 23, 5168.

36 S. Wu, S. Li, Q. Sun, C. Huang and M. K. Fung, Sci. Rep., 2016, 6, 25821.

37 I. Tanaka, Y. Tabata and S. Tokito, J. Appl. Phys., 2006, 99, 913.

38 Y. Miao, K. Wang, B. Zhao, L. Gao, P. Tao, X. Liu, Y. Hao, H. Wang, B. Xu and F. Zhu, Nanophotonics, 2018, 7, 295. 
39 T. Zhang, C. Shi, C. Zhao, Z. Wu, J. Chen, Z. Xie and D. Ma, ACS Appl. Mater. Interfaces, 2018, 10, 8148.

40 M. A. Baldo, C. Adachi and S. R. Forrest, Phys. Rev. B: Condens. Matter Mater. Phys., 2000, 62, 10967.
41 S. Reineke, K. Walzer and K. Leo, Phys. Rev. B: Condens. Matter Mater. Phys., 2007, 75, 125328. 